\title{
Participação, políticas públicas e o movimento LGBT brasileiro entre 2003 e 2014
}

\author{
Participation, public policies and the brazilian LGBT movement \\ between 2003 and 2014
}

\section{Douglas Santos Alves}

\section{Resumo}

$\mathrm{O}$ artigo analisa a relação entre o movimento de Lésbicas, Gays, Bissexuais, Travestis e Transexuais (LGBT) com os governos de Lula da Silva e Dilma Rousseff a partir das políticas participativas por eles implementadas. Estudos empíricos feitos pelo Instituto de Pesquisa Econômica Aplicada (IPEA) apontam para significativa ampliação da estrutura institucional de participação, centrada no aumento de Conferências Nacionais e Conselhos Nacionais de Políticas Públicas. Partindo de estudos qualitativos, a participação política do movimento LGBT como grupo subalterno gerou laços de dependência no que tange a recursos materiais e simbólicos, fazendo-o conformar-se no Estado e não diante deste. Isso repercutiu em sua autonomia e organização gerando a adesão e o consenso ativo do grupo subalterno junto ao bloco no poder. Ao comprometer a constituição do movimento enquanto sujeito político autônomo, a relação aponta para a hegemonia exercida pelo governo sobre a população LGBT.

\section{Palavras-chave}

Movimento LGBT; Hegemonia; Participação Política; Conferências Nacionais.

\section{Abstract}

The article analyzes the relationship between the lesbian, gay, bisexual, transgender (LGBT) movement with the governments of Lula da Silva and Dilma Rousseff based on their participatory policies. Empirical studies by the Institute of Applied Economic Research (IPEA) point to a significant expansion of the institutional structure of participation, centered on the increase of National Conferences and National Councils of Public Policies. Based on qualitative studies, the political participation of the LGBT movement as a subordinate group generated ties of dependence on material and symbolic resources, making the group conform within the State and not before it. This impacted on their autonomy and organization, generating the active adhesion and consensus of the subordinate group with the power bloc. By compromising the constitution of the movement as an autonomous political subject, the relation points to the hegemony exercised by the government over the LGBT population.

\section{Keywords}

LGBT Movement; Hegemony; Political Participation; National Conferences. 


\section{Introdução}

A ascensão da coalizão liderada pelo Partido dos Trabalhadores ao Governo Federal em 2003 marca uma mudança na relação entre sociedade civil e sociedade política. Estudos sobre o chamado Lulismo (SINGER, 2009; RENNÓ e CABELLO, 2010) trazem um interessante debate sobre as mudanças econômicas na vida das camadas de mais baixa renda da população, retomada do clientelismo e do personalismo político e possíveis realinhamentos ideológicos no cenário nacional. Mas o que chama a atenção é o apoio obtido junto a grupos específicos e atores políticos estratégicos, como associações empresariais e, com destaque, os movimentos sociais. Dada a trajetória histórica do PT, uma ampla expectativa de mudanças permeou a relação da sociedade civil (as organizaçóes de trabalhadores e movimentos sociais de cunho progressista) com o governo. Tal relação permitiu a Oliveira (2010, p. 25) afirmar que "já no primeiro mandato, Lula havia sequestrado os movimentos sociais e a organização da sociedade civil". A afirmação enfática se apoia no tipo de relação estabelecida entre sociedade civil e sociedade política ao longo do período.

Tomando tal relação como problemática geral, considera-se importante investigar como ela se materializou sob a forma de políticas públicas orientadas pela ampliação significativa da estrutura estatal de participação para os movimentos sociais em geral e o movimento de Lésbicas, Gays, Bissexuais, Travestis e Transexuais (LGBT) em particular. Este artigo visa, portanto, avaliar tal estrutura de participação bem como a efetividade das políticas voltadas ao público LGBT e os efeitos da participação juntamente com essas políticas públicas sobre a relação do movimento em questão com o Governo Federal. Ao fim, pretende-se apresentar subsídios para a formulação de uma hipótese de pesquisa que aponte para o papel da forma concreta de participação impulsionada pelo governo como meio para estabelecer uma relação de hegemonia sobre o movimento LGBT. 


\section{Participação e ampliação da sociedade politica}

A Constituição Federal de 1988 representa um marco na institucionalização de mecanismos de participação social na condução das políticas de governo. Desde a sua promulgação até o ano de 2010, o país realizou 92 conferências nacionais ${ }^{1}$, além da criação de dezenas de conselhos nacionais para elaboração, avaliação e monitoramento de políticas públicas. O período de 2003 a 2010, sob a gestão do presidente Lula, é considerado por alguns autores o momento de maior aprofundamento das políticas de participação social (AVRITZER, 2012; POGREBINSCH, 2012; POGREBINSCH e SANTOS, 2011; MACHADO, 2013). Somente neste período foram realizadas 74 dessas conferências, o que levou Avritzer (2012, p. 8) a caracterizar que "de fato, existe hoje uma política participativa no nível federal de governo centrada nas conferências nacionais". Isso permite afirmar que, com efeito, há uma relação diferenciada entre Estado e sociedade civil, expressa no significativo alargamento institucional das estruturas de participação.

Embora existam muitas leituras explicitamente otimistas, é preciso problematizar até que ponto o estreitamento da relação do Estado com a sociedade civil, em especial com os movimentos sociais e o movimento LGBT, significa efetivos avanços para estes últimos. Uma série de estudos realizados pelo IPEA ${ }^{2}$ apresenta um conjunto interessante de dados empíricos sobre as conferências nacionais e os conselhos de políticas públicas que permitem uma análise empiricamente mais embasada. Além disso, outros estudos permitirão apontar elementos contraditórios deste processo, sobretudo para a compreensão da relação que a sociedade civil estabelece com o Estado e o governo, o que permitirá problematizar a constituição do movimento LGBT como sujeito político autônomo a partir do novo momento iniciado em 2003.

A política de participação levada a cabo pelo governo Lula conseguiu atingir um número significativo de pessoas. Segundo Avritzer, as conferências nacionais alcançaram um percentual de 6,5\% da população brasileira (AVRITZER, 2012), sendo que cerca de $42 \%$ da população já ouviu falar dos eventos, o que sugere que este seja um procedimento conhecido das pessoas (AVRITZER, 2012).

Das 80 conferências nacionais analisadas por Pogrebinsch, entre 1988 e 2009, 13,8\% foram referentes aos Direitos Humanos; 16,3\% à Educação, Cultura, Assistência Social e Esporte; 16,3\% ao Estado, Economia e Desenvolvimento; 3,8\%

\footnotetext{
${ }^{1}$ Conforme dados da Secretaria Geral da Presidência da República.

${ }^{2}$ Ver Participação em Foco em: <http://www.ipea.gov.br/participacao/>.
} 
ao Meio Ambiente; 25\% ligadas à Saúde e 25\% às Minorias (POGREBINSCH, 2012). De 2003 até 2009, as conferências de minorias constituem quase um terço das conferências nacionais, 31\% contra 69\% (POGREBINSCH, 2012). Conforme a autora, a própria compreensão de "minorias" é alargada durante o governo Lula, abrangendo um conjunto cada vez mais amplo e heterogêneo de grupos sociais.

A convocatória desses eventos é capitaneada pelo poder executivo, por meio de decreto presidencial, portaria ministerial ou, em menor número, resolução dos conselhos (SOUZA et al., 2013). Em geral, as comissóes organizadoras das conferências têm uma composição média de $33 \%$ de representantes não governamentais, $34,6 \%$ de representantes governamentais e $32,41 \%$ de representantes dos conselhos, o que aponta para uma discreta predominância do poder governamental (SOUZA et al., 2013). No mesmo estudo, a média de participação de delegados é de 2.472 para 63 eventos analisados. Das conferências consideradas típicas pelas suas características 3 , 63\% das vagas para delegados foram ocupadas por representantes não governamentais e $37 \%$ por representantes ligados ao governo. A forma de participação dos delegados se dividiu em convidados, natos e eleitos, sendo que $83 \%$ previu a participação de delegados natos, geralmente os conselheiros dos conselhos nacionais, representantes de órgãos públicos, gestores das áreas políticas específicas ligadas ao tema da conferência e também representantes indicados de entidades nacionais da sociedade civil (SOUZA et al., 2013).

Em estudo realizado pelo IPEA, especificamente sobre as conferências com temáticas de minorias (POGREBINSCHI, 2012), constatou-se a realização de 20 conferências nacionais voltadas para a temática. Os nove temas que organizaram os eventos foram: "direitos da pessoa idosa", "direitos da pessoa com deficiência”, "gays, lésbicas, bissexuais, travestis e transexuais", "povos indígenas", "políticas públicas para as mulheres", "direitos da criança e do adolescente", "juventude", "promoção da igualdade racial" e "comunidades brasileiras no exterior". Destas nove áreas de políticas para minorias sociais e culturais, oito passaram a ser objeto de conferência nacional apenas a partir de 2003, com o início do governo Lula (POGREBINSCHI, 2012), sendo que a exceção são as conferências de direitos da criança e do adolescente, temática que é das mais institucionalizadas e que iniciou em 1997.

\footnotetext{
${ }^{3}$ Os critérios para a definição de conferências típicas foram: organização de responsabilidade de um órgão do Executivo ou de um conselho gestor; realização de etapas preparatórias; processos seletivos para escolha de representantes governamentais e não governamentais para a etapa nacional (SOUZA et al., 2013).
} 
De acordo com este estudo, 77,2\% das deliberações realizadas nas plenárias finais dos eventos ocorridos a partir de 2003 direcionaram-se ao poder executivo e o restante ao legislativo. No caso da conferência LGBT de 2008, foram encaminhadas, segundo a autora, 96 (62,7\%) diretrizes administrativas (para o executivo) contra 57 $(37,3 \%)$ diretrizes legislativas (para o legislativo), totalizando $153^{4}$ (100\%).

A predominância de diretrizes administrativas, além de fatores apontados pela autora, como o tempo para buscar consensos e a construção de coalizões em busca de maioria parlamentar, deve-se a que "as diretrizes de caráter administrativo dos grupos minoritários demandam a concretização de direitos já assegurados em lei ou a implementação de políticas já existentes" (POGREBINSCHI, 2012, p. 25).

Um estudo anterior (POGREBINSCHI e SANTOS, 2011) sugere que a realização das conferências nacionais produziu, desde 1988, forte efeito sobre a atividade legislativa no Congresso Nacional. Contudo, das proposiçôes e diretrizes das conferências (80 conferências desde 1988), somente 1,2\% virou efetivamente lei ${ }^{5}$. As áreas temáticas predominantes na produção legislativa "inspirada" pelas conferências nacionais concentram-se em direitos humanos, saúde, meio ambiente e minorias.

Segundo os dados apresentados, é a partir do governo Lula que há uma explosão de atividade legislativa com temática vinculada às proposições das conferências nacionais, embora o processo se inicie sob o governo de FHC. Isso decorre do fato de que é no governo Lula que ocorre a qualitativa expansão das conferências nacionais. Os dados sugerem:

haver uma afinidade entre o quadro político emergente com a vitória do PT nas eleições presidenciais e o crescimento da produção legislativa "acionada" pelas diretrizes das conferências (POGREBINSCHI e SANTOS, 2011, p. 292).

\footnotetext{
${ }^{4}$ A Conferência em questão aprovou mais de 500 resoluçóes, sendo que as 153 mencionadas são somente uma parte deste total.

${ }^{5} \mathrm{O}$ critério metodológico foi a pertinência temática entre a atividade legislativa (leis e emendas constitucionais) e as diretrizes aprovadas nas conferências, sendo que é possível não haver relação direta entre a lei específica e a diretriz definida na conferência.
} 
Em outro estudo (IPEA, 2012), foram mapeados 60 conselhos. Eles também são considerados peças-chave na arquitetura de participaçáo social durante o governo Lula. Segundo o estudo:

Conselhos são espaços participativos, que podem ser tanto consultivos como deliberativos, nos quais é prevista certa permanência no tempo. São compostos por representantes do poder público e da sociedade civil, esta sendo dividida em diferentes segmentos. Os conselhos têm como finalidade incidir nas políticas públicas de determinado tema, e suas atribuiçóes variam nos diversos contextos (IPEA, 2012, p. 14-15).

A participação em seu interior não é aberta a qualquer pessoa, tal como as conferências. Participam dos conselhos membros eleitos ou indicados, sendo que é necessário que os conselheiros tenham certa qualificação e identificação com a área de atuação do conselho. Chama a atenção o fato de que o governo é quem escolhe os representantes dos conselhos, seja diretamente indicando a pessoa, seja indicando a instituição, que por sua vez definirá a pessoa a representá-la:

Os conselhos são constituídos como espaços permanentes em que a representação se dá, em 30,6\% dos casos, por organizaçóes mencionadas nos próprios atos normativos do conselho e em 29\% dos conselhos por indicação feita pelo ministro ou por uma comissão referendada pelo dirigente do órgão ao qual o colegiado se vincula. Nessas duas formas de escolha de participantes, há um chamado oficial à representação, ou seja, por mais que o governo tenha sido incitado pela sociedade civil a criar espaços de diálogo, é ele que escolhe os representantes (IPEA, 2012, p 23-24).

Os conselhos também estiveram envolvidos de diferentes formas na organização de $43,5 \%$ das conferências nacionais (SOUZA et al., 2013). Isso, combinado com a representação dos conselheiros como delegados natos em parcela importante dos eventos, evidencia a relação mais ou menos orgânica entre conselhos e conferências. Além deste fato, os estudos mencionados também apontam para a atuação dos conselhos como complementar as conferências, particularmente durante o interregno de realização destas.

O que se pode reter dessas informaçóes é que, de fato, existe uma ampliação da estrutura institucional de participação e que isso atinge efetivamente a sociedade civil, estreitando sobremaneira os laços desta com a sociedade política. Desse modo: 
A ideia de democratização social através da participação constitui um fundamento importante de caracterização do projeto governista em curso, assumindo um lugar de destaque na configuração do discurso estatal (MACHADO, 2013, p. 185).

Conforme o autor citado, a participação é apresentada como o elemento de "novidade" no discurso governamental, com conteúdo de "ruptura histórica" com a lógica política até então dominante. O discurso da participação dá qualidade ao lugar ocupado pelo movimento social, produzindo identidade (MACHADO, 2013). Nesse sentido, o papel do governo Lula é decisivo.

\section{Contradições e limites da politica de participação}

Embora a maioria dos estudos apresentados expresse forte otimismo com a política de participação realizada ao longo do governo Lula e também do governo Dilma, algumas contradiçóes podem ser apontadas. Dentre elas devem ser citadas a fragmentação institucional do arranjo participativo:

Este arranjo institucional pode ter dificultado o fortalecimento das iniciativas de gestão participativa quando separou a articulação com a sociedade civil - responsabilidade da Secretaria Geral - da integração das açóes governamentais - responsabilidade da Casa Civil. Isso fez com que as articulaçóes com a sociedade ficassem à parte das ações de integração intergovernamental, possivelmente dificultando a implementação de decisóes cuja responsabilidade ultrapassava a competência do órgão responsável pelo espaço participativo (TEIXEIRA et al., 2012, p. 13).

Ao mesmo tempo, isso possibilitou ao governo exercer maior controle direto sobre a participação da sociedade civil, de modo a isolar certos conflitos e colocar os movimentos diretamente diante da presidência: 
Esta estratégia organizacional permitiu ao governo alguma margem de manobra para dotaçóes orçamentárias e desenvolvimento de ações sobre temas polêmicos, evitando conflitos com outros âmbitos estatais, como por exemplo, o poder legislativo ou ministérios geridos por partidos da base aliada que não compactuassem integralmente com algum posicionamento assumido pelo governo (MACHADO, 2013, p. 163).

Sobre o problema da representaçáo, deve-se destacar a carência de mecanismos de controle pelos representados, dependendo essencialmente da boa vontade dos representantes: "os mecanismos que permitem que os representados desautorizem o representante caso desaprovem sua atuação não foram criados ainda. $O$ vínculo entre representante e representado ainda depende da boa vontade do primeiro" (TEIXEIRA et al., 2012, p. 23). Além disso, o próprio papel do governo como decisivo na definição dos representantes, no caso dos conselhos, reforça o problema. Mas mesmo quando ocorre eleição de representantes, isso não significa maior autonomia da sociedade civil na participação, uma vez que não há garantia de participação dos representados no processo de escolha:

As eleiçóes nos conselhos são um processo em que somente potenciais representantes, que preenchem determinados requisitos, podem participar. Assim, uma organização só passa a fazer parte do conselho quando é reconhecida por outros representantes ou pelo governo como legítima vocalizadora de interesses de públicos a serem representados no órgão (TEIXEIRA et al., 2012, p. 25).

Coloca-se, portanto, o problema da determinação da legitimidade dos representantes, o que sugere que o governo tenha papel decisivo na definição de quem pode exercer a representação. Este ponto não é menor, uma vez que diz respeito a autonomia dos movimentos que participam.

Outra questão de suma importância é o papel do governo nas conferências e conselhos. Uma vez que atuam como delegados e representantes com direito a voz e voto, e que seu peso é geralmente grande (maior que um terço), concorda-se com a observação dos autores de que: 
Cairia por terra a percepção de que as conferências são processos de escuta de demandas sociais e ganharia força a visão do espaço como arena de interlocução e disputa entre governo e sociedade. Afinal, os representantes governamentais não estariam incumbidos apenas de promover e organizar as conferências, ou mesmo de mediar conflitos de posições, seriam eles também agentes no embate de ideias (TEIXEIRA et al., 2012, p. 34).

Tais elementos levam os autores a uma conclusão contrária à maior parte das avaliações apresentadas:

O que se observa é que a força de autorização para a representação nos espaços participativos nacionais estudados não emana dos representados e sim do órgão que institui o espaço ou do reconhecimento por organizaçóes que já estão legitimadas para atuação naquela instância (TEIXEIRA et al., 2012, p. 41).

Deste modo, tem-se um cenário de ampliação significativa dos espaços institucionais reservados para a participação da sociedade civil ao longo do governo Lula, porém, observaçôes mais detalhadas sugerem contradiçôes importantes nessa ampliação. Ao analisar a relação do movimento LGBT com o Estado a partir de tais espaços participativos é possível levantar um conjunto de problemas que sugere não o fortalecimento do movimento em questão, mas sua perda de autonomia. Isso é agravado quando confrontada tal situação com a falta de efetividade das políticas públicas para esta população.

\section{O movimento LGBT e as politicas públicas}

Conforme apontam Simões e Facchini (2009), ao longo dos anos 1990, após o efeito devastador da epidemia de HIV-AIDS, inicia-se o chamado "reflorescimento" das organizações LGBTs. A marca predominante, conforme já apontado, é a sua reorganização a partir do formato das ONGs. Sua relação com o Estado é mais estreita e menos conflitiva, mediada pelas políticas de saúde e prevenção às DST/AIDS. Durante esse período, a principal frente de atuação do movimento é o poder legislativo.

Contudo, a partir de 2003, inicia-se uma mudança na atuação do movimento. Seu foco passa a ser o poder executivo e sua lógica de ação passa a ser a participação nos espaços criados pelo governo e a colaboração ativa com as políticas elaboradas por este. Das iniciativas do governo voltadas para a populaçáo LGBT, 
destacam-se o programa Brasil Sem Homofobia - BSH - (2004); a primeira Conferência Nacional LGBT (2008); a criação do Plano Nacional de Promoção da Cidadania e Direitos Humanos de LGBTs - PNPCDH-LGBT - (2009), o chamado Plano Nacional LGBT; a criação do Conselho Nacional de Combate à Discriminação de LGBT - CNCD/LGBT - (2001-2010) ${ }^{6}$ e do terceiro Plano Nacional de Direitos Humanos - PNDH-3 - (2009). Há ainda a segunda Conferência Nacional LGBT realizada no governo de Dilma Rousseff (2011) e a terceira, conjunta com outras temáticas, realizada em 2016. Estas ações podem ser consideradas como os principais momentos das políticas públicas do governo para a população LGBT e da atuação do movimento junto ao Estado (MELLO, AVELAR e MAROJA, 2012).

Tanto o BSH quando o PNDH-3 contaram com a importante colaboração das entidades do movimento LGBT, ao passo que a primeira conferência nacional contou com a participação de 10.000 pessoas em suas três etapas de realização, e suas propostas foram a base para o Plano Nacional LGBT. Do mesmo modo, o Conselho LGBT conta com 30 membros, sendo metade composta por representantes governamentais e a outra metade por representantes não governamentais, dentre os quais, membros da comunidade científica, da sociedade civil e das organizaçóes do movimento LGBT?.

Desse modo, pode-se afirmar que a política de participação implementada pelo governo Lula incorporou o movimento LGBT desde os espaços participativos criados e também a partir dos programas elaborados. Com isso, é possível analisar a relação do movimento com o Estado e o governo sob o prisma das contradiçóes que tal política encerra.

Num estudo aprofundado, Machado (2013) afirma que a política nacional de participação do governo tratou a participação da sociedade civil como um fim em si mesma. Disso desdobra-se que os espaços criados foram preenchidos em boa medida por lideranças oriundas do movimento LGBT, produzindo uma zona de intersecção entre Estado e sociedade civil cujas fronteiras ficaram relativamente borradas. A característica geral da política de participação, segundo o autor, foi marcada pela

\footnotetext{
${ }^{6}$ A criação do CNDC/LGBT percorreu várias fases, iniciando em 2001 ligado ao combate à discriminação racial. Em 2005 passa a incorporar explicitamente LGBTs e em 2010 é constituído como tal, por meio do decreto n. 7.388/2010 (BRASIL, 2010).

${ }^{7}$ Para um estudo detalhado do conselho, ver IPEA (2012) relatório de pesquisa O Conselho Nacional de Combate à Discriminação e Promoção dos Direitos de LGBTs na visão de seus conselheiros.
} 
mobilização de identidades cada vez mais fixas e fragmentadas, sendo definidas pelo próprio governo ${ }^{8}$.

Outro elemento importante é o fato de que estes espaços de participação não contam com poder efetivo de decisão, seja por falta de orçamento ou por serem essencialmente consultivos, o que reforça a característica da participação como fim em si mesma. O autor conclui que os espaços de participação atuam como forma de domesticação dos conflitos, absorvendo demandas oriundas do movimento LGBT sem conseguir avançar na sua efetivação em políticas públicas. Os conflitos que por ventura surgem entre movimento e governo terminam por ser neutralizados. Isso sugere que tais espaços institucionais atuam como fator de mediação de conflitos e de demandas entre o movimento e o Estado/governo em detrimento do movimento.

A partir das propostas do $\mathrm{BSH}$, foram criados 45 Centros de Referência em Direitos Humanos e Cidadania Homossexual - CRDHCH - e mais 8 Núcleos de Referência em Direitos Humanos e Cidadania Homossexual em universidades públicas entre 2005 e 2006. Contudo, em atividade de avaliação da SDH em 2008, concluiu-se que predominava uma descontinuidade dos trabalhos em virtude da falta de recursos, levando ao fechamento de muitos dos centros (MELLO, AVELAR e MAROJA, 2012).

O Plano Nacional LGBT também seguiu uma trajetória problemática. Tendo sido aguardado como principal resultado da primeira conferência nacional LGBT, o documento sequer foi publicado na página de web da SDH. Além disso, não foi instituído pelo governo na forma de decreto ou portaria, não ganhando existência formal (MELLO, AVELAR e MAROJA, 2012).

Já o PNDH-3 previa apenas uma ação que dependia do poder legislativo, enquanto que o PNDH-2 previa cinco ações com anuência do Congresso Nacional. Assim, "essa mudança de estratégia sinaliza a renúncia formal do poder executivo de atuar na esfera do Congresso Nacional com vistas à aprovação de proposições legislativas fundamentais para a população LGBT no Brasil" (MELLO, AVELAR e MAROJA, 2012, p. 305). Sobre a relação entre os Três Poderes, deve-se recordar que a principal conquista do movimento LGBT em âmbito nacional, o reconhecimento da união civil de pessoas do mesmo sexo (2011), e posteriormente o reconhecimento

\footnotetext{
${ }^{8}$ Este ponto é objeto de críticas pelos teóricos identificados com as correntes pós-estruturalismo e queer. Judith Butler (2013) já questionava o problema da representatividade da mulher a partir dos radicais questionamentos feitos à categoria "mulher". Ao mesmo tempo, as identidades que atravessam a sigla LGBT têm sido cada vez mais questionadas em sua essencialidade e fixidez.
} 
do casamento homoafetivo (2013), veio do poder judiciário. Também serve de exemplo o caso do Projeto Escola Sem Homofobia, que previa a distribuição de 6.000 kits anti-homofobia para escolas públicas do país, e que por uma forte mobilização de parlamentares da bancada evangélica no Congresso Nacional fez a presidente Dilma Rousseff recuar de sua implementaçâo, anunciando pessoalmente o cancelamento do projeto?. Isso demonstra uma estratégia de não levar as demandas concretas e específicas do movimento para o poder legislativo em virtude dos possíveis confrontos que gerariam com a base aliada do Governo Federal. Nesse sentido, restringir a relaçáo do movimento com o governo aos espaços criados parece ser, de fato, eficiente para conter conflitos que possam emergir com outros segmentos e poderes que sustentam o governo.

Sob um ponto de vista mais jurídico do que político, os planos e programas de ação que o Estado elaborou não conseguem se materializar em ações efetivas: "o grande culpado' pela falta de efetividade dos planos e programas é justamente o caráter meramente programático dos dispositivos que os compõem" (MELLO, AVELAR e MAROJA, 2012, p. 292). Ou seja, não podem ser traduzidos em direitos, "mas apenas em expectativas de direitos, pois explicita[m] os fins, sem indicação de meios para alcançá-los" (MELLO, AVELAR e MAROJA, 2012, p. 292). Isso remete diretamente ao problema da ausência de arcabouço jurídico que garanta a materialização das políticas delineadas nos planos e programas, o que, por sua vez, recoloca o problema da relação com o legislativo e o debate da "grande política" e os conflitos que tais demandas podem gerar.

Em outro estudo de balanço das políticas públicas para a população LGBT, a avaliação geral que se faz é de que as iniciativas esbarram nos seguintes problemas: a) a falta efetiva de leis que garantam que as políticas se tornem políticas de Estado para além das oscilaçóes conjunturais enfrentadas pelos governos de turno; b) os documentos que preveem ações, quando comparados com leis, têm força normativa secundária (decretos, portarias, resoluções, recomendaçôes e instruçóes, a exemplo do BSH e do Plano Nacional LGBT); c) a falta de definição específica de recursos na Lei de Diretrizes Orçamentárias, no Plano Plurianual e na Lei Orçamentária Anual; d) a fragilidade institucional que dificulta a realização de ações conjuntas, transversais e intersetoriais entre órgãos do governo e instâncias de poder municipal, estadual e federal (MELLO, BRITO e MAROJA, 2012).

\footnotetext{
${ }^{9} \mathrm{O}$ anúncio foi feito na grande mídia e marcou um dos pontos de maior conflito entre o movimento LGBT brasileiro e o Governo Federal.
} 
Desse modo, constata-se a imensa dificuldade em materializar as políticas públicas elaboradas com a participação do movimento LGBT, que ficam limitadas a condição de fins sem os meios adequados para sua realização ${ }^{10}$. O que resta como política efetiva, portanto, é a participação em si mesma.

\section{Participação nos espaços institucionais}

A constituição do movimento LGBT brasileiro como sujeito político parece sofrer os efeitos de seu processo de institucionalização. Este processo se inicia ainda nos anos 1990 quando o formato organizativo de ONG passa a predominar. Contudo, a política de participação social, ancorada no alargamento dos espaços institucionais criados a partir de 2003, parece ter produzido um forte impacto.

Num estudo realizado sobre os grupos LGBTs de Belo Horizonte é destacada a trajetória e os efeitos sofridos pela aproximação e articulação com a institucionalidade:

os grupos organizados foram sendo assimilados e diminuíram sua capacidade de interpelação, já que estes espaços são controlados por regras, procedimentos institucionais e mecanismos burocráticos que limitam as possibilidades de enfrentamento, sobretudo das lideranças que se envolveram diretamente com órgãos governamentais [...] Ressalta-se que isto se dá em um momento no qual a relação dos movimentos sociais com o Estado é marcada pela ampliação da assimilação, em grande medida motivada por ações do governo federal, dos discursos militantes para a adesão a um discurso popular hegemônico que tende a neutralizar divergências (PRADO e MACHADO, 2014, p. 160).

Os fatores apontados para isso remetem a uma crescente relação financeira entre movimentos e poder público, com editais para projetos e o financiamento público das Paradas do Orgulho LGBT. Outro fator é a incorporação de lideranças dos movimentos em funções e cargos públicos como Secretarias de Direitos

\footnotetext{
${ }^{10}$ Uma notável exceção são as políticas na área de saúde, particularmente os planos ligados à prevenção e tratamento de DST/AIDS. Estes, contudo, iniciaram ainda na década de 1990. Tais políticas poderiam ser consideradas como o marco de referência para as demais políticas cobradas pelo movimento exatamente por não sofrerem de boa parte das limitações e deficiências institucionais, jurídicas e orçamentárias apresentadas.
} 
Humanos, nos Centros de Referência, além dos espaços nacionais como o Conselho Nacional LGBT ${ }^{11}$.

Em sua tese de doutoramento, a partir de entrevistas em profundidade colhidas entre lideranças do movimento, algumas das quais que circularam pelo Conselho Nacional LGBT, Machado (2013) afirma de modo enfático que a zona de intersecção entre sociedade civil e Estado, cujas fronteiras ficam borradas, encerra a contradição na qual, geralmente, "perder o poder equivale a perder o emprego". Isso remete diretamente à questão do transformismo ${ }^{12}$ apresentada por Gramsci.

O fato é que, a despeito da falta de efetividade das políticas públicas para LGBTs, a política de participação implementada a partir de 2003 implica numa distribuição de recursos materiais e simbólicos para lideranças de organizações do movimento produzindo seu consenso ativo. Ao mesmo tempo, tal política pauta-se pela mobilização de identidades fixas, previamente definidas pelo governo, que são a base da estruturação da participação. A característica predominante, segundo Machado (2013), é a fragmentação das identidades, dentro de uma lógica competitiva entre segmentos identitários que se mobilizam por tais recursos. Chega-se, portanto, a situações onde mulheres lésbicas negras entram em atrito com jovens gays estudantes que por sua vez se confrontam com travestis e transexuais, fator que dificulta a articulação e elaboração de pautas conjuntas entre os segmentos. O efeito geral deste processo é a tendência de o movimento manter-se sob a condição do que Gramsci chama de momento econômico-corporativo.

Diversos estudos qualitativos têm constatado que militantes e lideranças consideram de grande importância a participação nos espaços institucionais, particularmente nos espaços criados pelo Governo Federal, por significarem maior visibilidade política e institucional (MACHADO e PRADO, 2014; MACHADO, 2013; FONSECA, NASCIMENTO e MACHADO, 2007). Isso coloca uma questão

\footnotetext{
${ }^{11}$ Numa reflexão interessante sobre o tema, Abers e Bülow (2011, p. 66) afirmam que: "No contexto de um crescente interesse na democracia e na participação em processos decisórios, os ativistas, frequentemente, cruzam a fronteira entre o Estado e a sociedade, trabalhando em alguns momentos em organizaçóes da sociedade civil e em outros momentos em órgãos estatais. Essa tem sido uma tendência em uma variedade de tipos de movimentos sociais, e tem sido notada e analisada na literatura latino-americana".

${ }^{12} \mathrm{O}$ conceito de transformismo ou transformismo de classe refere-se ao processo de assimilação de intelectuais e quadros dos grupos subalternos pelos grupos hegemônicos, de modo a comprometer a autonomia dos subalternos e minimizar resistências no processo de direção política determinado pela fração hegemônica.
} 
fundamental acerca da constituição do movimento LGBT como sujeito capaz de colocar-se na cena social e política do país em defesa de seus direitos: o problema da sua legitimação por meio do Estado. Nesse ponto, ganham importância as características político-institucionais da ampliação dos espaços participativos.

Embora com uma linha de análise oposta a que é apresentada neste texto, a passagem a seguir é elucidativa:

Tendo como ponto de partida o Poder Executivo, que as convoca por meio de decretos presidenciais e atos normativos de seus ministérios e secretarias, as conferências nacionais o têm também como seu natural ponto de chegada. Se é o Executivo o poder do Estado responsável por formular e implementar políticas públicas, e se ele convoca e organiza as conferências nacionais justamente com essa finalidade, parece ser natural que as diretrizes aprovadas tendam a demandar mais a ação do Executivo a fim de serem cumpridas (POGREBINSCHI, 2012, p. 28).

A passagem evidencia o papel do governo como fator principal na organização e mobilização das e para as conferências nacionais. Além de ponto de partida, ele se torna o ponto de chegada, o que contradiz a falta de arcabouço jurídico próprio para garantia dos direitos de LGBTs, que por sua vez demandaria maior pressão sobre o poder legislativo.

O caso de definição da composição dos conselhos também é um exemplo da influência do governo na determinação da legitimidade de quem, dentro da sociedade civil, está apto a representá-la. Ainda que metade dos conselheiros seja de representantes eleitos, não significa maior autonomia da sociedade civil na participação. O controle imposto na definição de escolha do representante de uma organização é, na verdade, um mecanismo de conferência de legitimidade por parte do governo, de quem são os autênticos porta-vozes da sociedade civil.

Desta forma, a eleição de uma organização para um conselho é mais do que a legitimaçáo do papel de porta-voz pelos próprios representados - é, em realidade, o reconhecimento, por parte de outros possíveis representantes, da aptidão da instituição para dar voz a determinados interesses (TEIXEIRA et al., 2012, p. 25).

Ao mesmo tempo, isso também representa, para tais organizaçóes, a possibilidade de obterem sua legitimaçáo frente às demais organizaçóes da sociedade 
civil com as quais disputam. Assim, o governo atua praticamente como árbitro sobre conflitos e disputas internas às organizaçóes e movimentos sociais.

\section{Apontamentos}

O alargamento da estrutura de participação social implementado durando o governo Lula e continuado pelo governo de Dilma Rousseff constitui-se como marca destes governos e, de fato, representa um relevante aprofundamento da participação. Contudo, existem problemas e contradiçóes que impedem leituras demasiado otimistas. Fatores como fragmentação institucional, caráter consultivo de tais espaços mais do que deliberativo, o próprio peso e o papel do poder executivo, os mecanismos de definição dos representantes, entre outros, afetam sobremaneira o seu funcionamento.

Em contrapartida, as políticas propostas, particularmente para a população LGBT, não conseguiram obter a efetividade desejada. A falta de recursos financeiros, de arranjos institucionais mais eficientes e particularmente a ausência de um arcabouço jurídico que garanta força normativa suficiente para a sua aplicação reforçam seu caráter de políticas de cunho programático.

Além disso, a política de participação do governo pautou-se pela mobilização de identidades fixas para participar dos espaços criados, o que no caso de LGBTs pode ser considerado problemático. Também a absorção de lideranças e quadros do movimento para dentro de tais espaços, inclusive por meio da lógica da fragmentação identitária, parece criar um terreno favorável a maior competitividade e disputa por legitimidade e por recursos entre os grupos que constituem o movimento. Tal como sugeriu Coutinho (2010), um traço bastante característico do governo Lula, embora já presente no governo Cardoso, é o transformismo, na forma da cooptação das principais lideranças da oposição pelo bloco no poder. Isso se realiza, ainda segundo o autor, pelo jogo entre formas da "pequena" e "grande" política.

Recuperando brevemente o debate que Gramsci (1999-2002) realiza sobre a "grande política" e a "pequena política", é possível afirmar que o marxista italiano baseia-se no argumento de que a "grande política" centra-se em projetos estratégicos e ideologias orgânicas. Representa os projetos de sociedade e expressa as diferentes visões de mundo das classes, frações de classes e grupos sociais. Trata-se da luta de hegemonias. Já a "pequena política” é aquela dos corredores, dos interesses imediatos e das intrigas palacianas. Sem tocar nas questóes estratégicas, ela transforma as questóes políticas em meramente técnicas ou administrativas, esvaziando o seu 
conteúdo. Conforme sugeriu o marxista italiano, reduzir a "grande política" à "pequena política" é parte da "grande política".

Coutinho (2010) sustenta que sob a gestão do presidente Lula prevaleceu a hegemonia da pequena política. Segundo o autor (2010, p. 31), "a hegemonia da pequena política baseia-se precisamente no consenso passivo". Isso significa a ausência ou o substancial enfraquecimento da participação ativa das massas e do papel protagônico de suas organizações (sociedade civil), deixando espaço para a "aceitação resignada do existente como algo 'natural”' (COUTINHO, 2010, p. 31). Desse modo, a grande política, tal como afirmara Gramsci, também é feita quando é reduzida à pequena política. Nas palavras de Coutinho (2010, p. 32), "é por meio desse tipo de redução, que se desvaloriza a política enquanto tal, que se afirma hoje a quase incontestada hegemonia das classes dominantes". Um dos efeitos disso é o da manutenção e reforço do momento econômico-corporativo ${ }^{13}$ dos grupos subalternos, o que permite manter as contradições em estado latente e pouco visível.

O processo de "sequestro" dos movimentos sociais, ou de exercício da direção política sobre eles, exigiu um conjunto de iniciativas tanto políticas quanto, e principalmente, institucionais. A chamada "pequena política" demandou certo equilíbrio de compromisso para ser viabilizada, e isso ocorreu a partir dos mecanismos de participação social que marcaram a gestão do PT no Governo Federal. As expectativas geradas pela eleição de Lula e depois de Dilma foram canalizadas para espaços participativos criados pelo governo. Com isso, o papel ativo e protagônico da sociedade civil não foi neutralizado, ao contrário, foi submetido a esferas da sociedade política e mobilizado pelas iniciativas do próprio governo, produzindo adesão e consenso a este. A própria lógica de funcionamento desses espaços, como parte de um todo maior, auxiliou a reduzir a participação à pequena política, ainda que recoberta e legitimada por um discurso de ampliação da democracia.

Tais fatores, combinados com o papel do governo em auferir legitimidade aos sujeitos políticos da sociedade civil, levam a desenvolver a hipótese de que, no processo de constituição do movimento LGBT como sujeito político no interior da sociedade civil, o Estado, por meio do governo, é utilizado como fator mediador em

\footnotetext{
${ }^{13} \mathrm{O}$ chamado momento econômico corporativo é detalhado na obra de Gramsci como certo ponto de desenvolvimento de um dado grupo social no qual se constata incapacidade de se produzir laços de identidade e solidariedade mais amplos, para além do grupo específico, e por consequência, de tornar suas aspirações e demandas em projeto político propriamente dito.
} 
sua constituição mesma como grupo subalterno. Isso implica na dependência do reconhecimento e na dependência de determinados e escassos recursos materiais e simbólicos oriundos do poder executivo para o movimento constituir-se e reconhecerse como tal. Ou seja, o grupo subalterno passa a constituir-se no Estado sob a tutela do governo. Coloca-se, portanto, o problema do enfraquecimento da participação ativa e protagônica da sociedade civil, que passa a ser determinada pelo bloco no poder por meio dos espaços participativos estatais. Assim, o problema da subordinação mantém-se, porém sob outra forma, a da presença e atuação do movimento LGBT junto ao Estado sob modos por este determinados. A partir das relações estabelecidas entre sociedade civil e sociedade política, por meio da ampliação da última, tal hipótese nos remete ao problema da hegemonia, em sentido gramsciano, exercida pelo governo sobre os movimentos sociais e o movimento LGBT em particular.

- Douglas Santos Alves é Doutor em Ciência Politica, pela Universidade Federal do Rio Grande do Sul. E Professor de Ciência Politica da Universidade Federal da Fronteira Sul. E-mail: douglasrev@yahoo.com.br.

\section{Referências}

AVRITZER, Leonardo. Conferências Nacionais: Ampliando e Redefinindo os Padróes de Participação Social no Brasil. Texto para discussão 1739. Rio de Janeiro: Ipea, 2012. Disponível em: <http://www.ipea.gov.br/participacao/estudos-do-ipea/conferencias2>. Acesso em 20 set. 2015.

BRASIL. Decreto n. 7.388, de 09 de dezembro de 2010. Dispóe sobre a composição, estruturação, competências e funcionamento do Conselho Nacional de Combate à Discriminação CNCD. Diário Oficial, Brasília, DF, 10 dez. 2010.

BUTLER, Judith. Problemas de gênero: feminismo e subversão da identidade. Rio de Janeiro: Civilização Brasileira, 2013. 
COUTINHO, Carlos Nelson. A hegemonia da pequena política. In: OLIVEIRA, Francisco de; BRAGA, Ruy; RIZEK, Cibele (Orgs.). Hegemonia às avessas. Sáo Paulo: Boitempo, 2010. p. 29-43. FONSECA, Carlos Magno; NASCIMENTO, Lúcia Aparecida; MACHADO, Frederico Viana. Dilemas Contemporâneos dos Movimentos Sociais GLBT. In: MAYORGA, Claudia; PRADO, Marco Aurélio Máximo (Orgs.). Psicologia Social: Articulando Saberes e Fazeres. Belo Horizonte: Autêntica, 1 ed., v. 1, 2007.

GRAMSCI, Antonio. Cadernos do Cárcere. Rio de Janeiro: Civilização Brasileira, v. 6, 1999-2002.

IPEA. O Conselho Nacional de combate à Discriminação e Promoção dos Direitos de Lésbicas, Gays, Bissexuais, Travestis e Transexuais na Visão de seus Conselheiros. Relatório de Pesquisa. Projeto Conselhos Nacionais: perfil e atuação dos conselheiros. Brasília, 2012.

MACHADO, Frederico Viana. Do estatal à política: uma análise psicopolítica das relaçóes entre o Estado e os movimentos de juventudes e LGBT no Brasil (2003-2010). 370 f. Tese (doutorado). Universidade Federal de Minas Gerais, Faculdade de Filosofia e Ciências Humanas. Belo Horizonte, 2013.

MEllO, Luiz; AVELAR, Bruno Rezende de; MAROJA, Daniela. Por onde andam as Políticas Públicas para a População LGBT no Brasil. Revista Sociedade e Estado, v. 27, n. 2, maio/agosto, 2012.

MELLO, Luiz; BRITO, Walderes; MAROJA, Daniela. Políticas públicas para a população LGBT no Brasil. In: Cadernos Pagu. Campinas, n. 39, julho/dezembro, 2012.

OLIVEIRA, Francisco de. Hegemonia às avessas. In: OLIVEIRA, Francisco de; BRAGA, Ruy; RIZEK, Cibele (Orgs.). Hegemonia às avessas. São Paulo: Boitempo, 2010. p. 21-28.

POGREBINSCHI, Thamy. Conferências Nacionais e Políticas Públicas Para Grupos Minoritários. Texto para discussão 1741. Ipea, Rio de Janeiro, 2012. Disponível em: <http://www.ipea.gov.br/participacao/estudos-do-ipea/conferencias2>. Acesso em 20 set. 2015.

POGREBINSCHI, Thamy; SANTOS, Fabiano. Participação como representação: o impacto das conferências nacionais de políticas públicas no Congresso Nacional. Dados - Revista de Ciências Sociais, v. 54, n. 3, 2011.

PRADO, Marco Aurélio Máximo; MACHADO, Frederico Viana. Muito além do arco-íris. A constituição de identidades coletivas entre a sociedade civil e o Estado. Annual Review of Critical Psycology, n. 11, 2014.

RENNÓ, Lucio; CABELLO, Andrea. As bases do Lulismo: A volta do personalismo, realinhamento ideológico ou não alinhamento? Revista Brasileira de Ciências Sociais, v. 25, n. 4, p. 30-61, 2010.

SIMÓES, Júlio Assis; FACCHINI, Regina. Do movimento homossexual ao LGBT. São Paulo: Editora Fundação Perseu Abramo, 2009.

SINGER, André. Raízes ideológicas do Lulismo. Novos estudos, n. 85, p. 83-101, 2009.

SOUZA, Clóvis Henrique Leite; CRUXÊN, Isadora Araújo; ALENCAR, Joana Luiza Oliveira; LIMA, Paula Pompeo Fiuza; RIBEIRO, Uriella Coelho. Ampliação da Participação na Gestão Pública: um estudo sobre Conferências Nacionais realizadas entre 2003 e 2011. Relatório de Pesquisa. Ipea, 2013. Disponível em: <http://www.ipea.gov.br/participacao/estudos-do-ipea/conferencias $2>$. Acesso em 20 set. 2015.

TEIXEIRA, Ana C. T.; SOUZA, Clóvis H. L.; LIMA, Paula P. F. Arquitetura da Participação no Brasil: Uma Leitura Das Representaçóes Políticas em Espaços Participativos Nacionais. Texto para 
168 | Douglas Santos Alves

discussão 1735. Ipea, Rio de Janeiro, 2012. Disponível em: <http://www.ipea.gov.br/participacao/estudos-do-ipea/conferencias2>. Acesso em 20 set. 2015.

Texto recebido em 05 de julho de 2017. Aprovado em 23 de outubro de 2017. 